\title{
Derleme/ Review \\ Batman İli Toprak ve Su Kaynaklarının Tarımsal Açıdan Değerlendirilmesi
}

\author{
Yusuf AYDIN* \\ Siirt Üniversitesi Ziraat Fakültesi, Biyosistem Mühendisliği Bölümü \\ *e-posta: yusufaydin056@gmail.com; Tel: 048421211 11; Fax: 04842231998
}

\begin{abstract}
Öz: Toprak ve su kaynakları, ülkelerin en değerli varlıkları olup, toplumların yaşamlarını sürdürebilmeleri için gereksinim duydukları gıdaların sağlanmasında asli unsurdur. Yenilenemeyen ve kıt kaynak olan toprak ve su kaynaklarının işletimi ve yönetimi, dünya ülkelerini küresel düzeyde koordineli çalışmaya yöneltmektedir. Küresel ısınmanın getirdiği değişimler sonucu oluşabilecek su kısıtı, sanayi ve kentsel gelişim ile artan nüfusa bağlı olarak artan gıda talebi, su kaynakları üzerindeki en önemli tehdit unsurlarıdır ve kaynaklar üzerindeki baskıyı artırmaktadır. Toplumlar gelecekle ilgili planlamalar yaparken, bu risk unsurlarını göz önüne almalı, toprak ve su kaynakları potansiyelini, kaynakları da koruyarak kullanmalı ve geliştirmelidir. Bu çalışmada, Batman İli toprak ve su kaynakları değerlendirilerek mevcut kaynaklar ve potansiyelleri ile işletiminde karşılan sorunlar irdelenmeye ve çözüm önerileri sunulmaya çalışılmıştır.
\end{abstract}

Anahtar kelimeler: Batman, Toprak ve su kaynakları potansiyeli

\section{Evaluation of Batman Province Soil and Water Resources in terms of Agricultural Perspectives}

\begin{abstract}
Soil and water resources are the most valuable assets of the countries and they are the essential element in the provision of food that societies need to survive. The operation and management of land and water resources, which cannot be renewed and scarce, directs the world countries to work in a coordinated manner at global level. As a result of the changes caused by the global warming, water demand, industrial and urban development and the increasing demand for food due to the increasing population are the most important threats on water resources and increases the pressure on resources. When planning for the future, societies should take into account these risk factors and use and develop the potential of land and water resources, while protecting resources. In this study, the resources and potentials of the Batman Province were evaluated and the problems encountered in the operation and the solutions were presented.
\end{abstract}

Keywords: Batman Province, Land and water resource potential

\section{Giriş}

$\mathrm{Su}$, canlı yaşamının en temel unsuru olmakla beraber, sürdürülebilir bir kalkınmanın sağlanmasında ve uygulanmasında en önemli faktörlerden birisidir. Yokluğunda yaşamın olmayacă̆ı, küresel kalkınmanın ve hatta canlı yaşamının ortadan kalkacağı bir kaynak olması nedeniyle ülkeler için de stratejik bir öneme sahiptir. Su kaynakları, tüm insanlığın ortak hazinesi olup, ekonomik veya ticari bir emtia olmamakla beraber toplumların ortak varlığıdır (Turan ve Eren 2008). Bu bakımdan ülkeler milli çıkarlarını korumak adına insanlığın ortak varlı̆ğ olan su kaynaklarını korumak, kollamak ve geliştirmek için küresel anlamda işbirliği yapmak zorundadırlar. Yaşamın devam ettiği her alanda, suyun kıt kaynak olduğu göz önüne alınarak planlamalar yapılmalıdır. Mevcut durumda var olan su kaynaklarının korunması ve geliştirilmesi yaşamsal öneme sahiptir. Küresel iklim değişiklileri nedeniyle azalması beklenen yeryüzü su kaynakları, artan nüfusa bağlı olarak artan gıda ve su talebi gibi iki önemli risk faktörü ile karşı karşıyadır (Çakmak ve Gökalp 2011). Mevcut su kaynaklarının sektörlere göre dağılımları incelendiğinde, tarımsal su kullanım oranı, kentsel ve sanayi kullanımı lehine değişme eğilimi göstermektedir. Bu durum, \%70 olan (Anonim 2018f) tarımsal su kullanımı üzerindeki baskıyı artırarak, gıda güvenliğini tehlikeye düşürmektedir. Artan nüfus ve gıda talebine karşılık, su kaynakları üzerindeki baskıların da artması, bu kaynakların daha rantabl kullanılması, sektörler arasında su kullanım kayıplarının en aza indirilmesi için daha etkin su kullanımı ve su yönetimi çalışmaları, havza düzeyinde planlanmalı ve kaynak potansiyeli bu yolla geliştirilmeli ve korunmalıdır (Aküzüm ve ark. 2010). Su kaynaklarının geliştirilmesi ve korunması sadece sorunlu alanlarla sınırlı kalmayarak ve mevcut kaynakların potansiyelinin artırılamayacağı göz önüne alınarak, kaynak potansiyeli riske edilmeden etkin bir su yönetimi ve su kullanımı sağlanmalıdır (Meriç 2004). Yenilenemeyen ve yeryüzünde sınırlı miktarda olan su kaynakları, Dünyanın üçte ikisini oluşturmaktadır. Ancak Dünyadaki toplam su varlığının \%97.5'i denizlerde ve okyanuslarda tuzlu su olarak bulunurken, bütün canlıların yaşam kaynağı olan tatlı su oranı \%2.5 düzeyindedir (DSİ 2018). Tatlı su 
kaynaklarının \%90’ı buzullarda ve yeraltında tutulması nedeniyle insanlığın kullanabileceği tatlı su miktarının ne kadar az olduğu ortaya çıkmaktadır. Nehirler, göller gibi tatlı su kaynakları, dünyadaki toplam suyun yaklaşık \%0.3' ünü oluşturmaktadır. Dünya nüfusunun yaklaşık \%20'sine karşılık gelen 1.5 milyar insan, yeterli içme suyundan yoksun iken, 2.2 milyar insan ise sağlıklı suya erişememektedir (Anonim, 2018h).

Dünyadaki mevcut tatlı su miktarının bu denli az olmasına karşın ülkemizde de durum bundan farklı değildir. Yerüstü su kaynakları, ülkemizde 26 akarsu havzasında bulunmaktadır. Ancak, yıllık toplam akış miktarının yaklaşık yarısı 5 havzadan (Fırat, Dicle, Doğu Karadeniz, Doğu Akdeniz ve Antalya) sağlanırken, kalan yarısı ise diğer 21 havzadan karşılanmaktadır. Batman ilinin de içerisinde bulunduğu Dicle ve Fırat havzalarının bu akış miktarı içerisindeki payı ise yaklaşık \%30 dolaylarındadır (Çakmak 2011). Halen ülke topraklarımızın 28 milyon ha' lık kısmı tarım alanı olarak kullanılmakta olup, bunun 8.5 milyon ha'lık kısmı ekonomik olarak sulanabilir düzeydedir. Tarım alanlarından iyi düzeyde verim alınabilmesi, ancak bu alanların \%93'ünün sulanması ile olanaklıdır. Tarımda kullanılan su miktarı 2000 yılında \%75 iken, bu oranın 2030 yılında \%65 olacağı öngörülmektedir (Karaman 2006). Bu azalmaya karşın, tarımda ortaya çıkması olası sorunların çözülmesi adına, tarımda etkin su kullanımının yanı sıra kaynak potansiyelini tehlikeye atmayan bir etkin su yönetimi, birim alandan alınan verimin artırılmasına yönelik çalışmalar ivedilikle yapılmalıdır. Toprak su kaynaklarının tek başına korunması yeterli olmayıp, bu kaynakların optimum kullanımını sağlayacak bir dengenin de oluşturulması gerekmektedir (Kıymaz 2011). Türkiye'nin yıllık ortalama yağış1 643 mm, yüzölçümünün 783577 km² olduğu göz önüne alındığında yıllık yağışla gelen su miktarı 501 milyar m³ $^{3}$ e karşılık

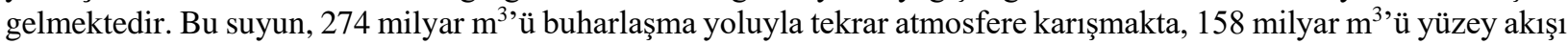
yoluyla denizlere ve göllere taşınmakta ve 69 milyar $\mathrm{m}^{3}$ yağış suyu ise yeraltı suyunu beslemektedir. Ancak, yeraltı suyunu besleyen bu miktarın 28 milyar $\mathrm{m}^{3}$ ’ ü tekrar pınarlar aracılığıyla yerüstü sularına karışmaktadır. Sınır aşan sular kapsamında ülkemize 7 milyar $\mathrm{m}^{3}$ suyun gelmesiyle, ülkemizin toplam yerüstü su potansiyeli $193 \mathrm{milyar}^{3}$ 'e ulaşmaktadır. Yeraltı suyunu besleyen 41 milyar $\mathrm{m}^{3}$ 'lük su miktarı da buna eklendiğinde, ülkemizin toplam yenilenebilir su hacmi 234 milyar $\mathrm{m}^{3}$ olmaktadır. Günümüz koşullarında tüketilebilecek yerüstü su hacminin, 95 milyar $\mathrm{m}^{3}$ 'ü yurtiçindeki akarsulardan, 3 milyar $\mathrm{m}^{3}$ 'ü ise yurtdışı kaynaklardan gelen olmak üzere $98 \mathrm{milyar} \mathrm{m}^{3}$ olarak hesaplanmaktadır. Buna 14 milyar $\mathrm{m}^{3}$ yeraltı su potansiyeli de eklendiğinde, ülkemizin yeraltı ve yerüstü olmak üzere toplam 112 milyar $\mathrm{m}^{3}$ olup, bunun 44 milyar $\mathrm{m}^{3}$ 'ü kullanılabilmektedir (DSİ 2018). Buna göre, ülkemizin su zengini olduğunu söyleyebilmek olanaksızdır. TUİK nüfus senaryolarına göre, ülkemiz nüfusunun 2030 yılında 93328574 ve 2080 yılında ise 107100904 olacağı öngörüsünden hareketle, mevcut durumda $1.519 \mathrm{~m}^{3}$ olan kişi başı su tüketiminin 2030 ve 2080 yıllarında sırasıyla $1120 \mathrm{~m}^{3}$ ve $1000 \mathrm{~m}^{3}$ 'ün altında olacağı öngörülmektedir (TUİK 2018). Batman İli yeraltı su kaynakları potansiyeli bakımından oldukça zengindir. İlin fazla engebeli olmayan ve Batman çayı etrafında bulunan verimli toprakları, yeraltı suyunun yer yer 10 m'ye kadar yükselmesi, yeraltı suyuna erişimin daha kolay olduğunu göstermektedir. Belirtilen alanlarda yapılan tarımsal faaliyetlerde suyun çevre ve toprak sorunu oluşturmadan etkin kullanımını ve birim alandan alınan verimin artırılmasına yönelik uygulamaların yapılmasını ve tedbirlerin alınmasını zorunlu kılmaktadır.

Bu çalışmada Batman ili toprak ve su kaynakları potansiyeli incelenerek, mevcut durum, sorunlar ve çözüm önerileri geliştirilmesi üzerinde durulmuştur.

\section{Coğrafik Konum}

Batman, Dicle havzasında, batı-doğu doğrultusunda il topraklarından geçen Dicle nehri ile Batman çayı kenarındaki verimli ovalardan oluşan düz bir alan üzerine yerleşiktir. Coğrafik olarak kuzey ve kuzeydoğusu sarp, yüksek ve dağlık olup, güney tarafı ise engebeli yapıya sahiptir. Doğusunda Siirt, batısında Diyarbakır, Kuzeyinde Bitlis ve Muş, güneyinde ise Mardin illeri ile çevrili, $41^{\circ} 10^{\prime}$ ve $41^{\circ} 40^{\prime}$ doğu boylamları ile $38^{\circ} 40^{\prime}$ ve $37^{\circ} 50^{\prime}$ kuzey enlemleri arasında yer almakta olan ilin denizden yüksekliği 540-560 m arasında değişmektedir (Şekil 1). İli çevreleyen Meleto Dağı, Sason (Aydınlık), Aşik (Selaş), Subaşı (Züpşer), Kuşaklı (Halkız), Taştepe (Golat), Karakaş, Avcı (Karamelik), Kortepe Dağı, Taç (Arvı), Çikolatatepe, Meydanok Tepesi, Kıradağ ve Raman dağları olarak sayılabilir. İlde verimli sulanabilir alanlar, Batman ve Beşiri ovaları ile Meleto yaylasında bulunmaktadır. Batman, önceleri Siirt ili Beşiri ilçesine bağlı bir köy iken, 1288 m rakımlı Raman dağında 1948 yılında petrol bulunmasından sonra hızla gelişerek, bağlı olduğu Siirt İlini de geride bırakarak 1990 yılında İl statüsüne kavuşmuştur (Anonim, 2005). TUIKK tarafindan yapılan İllere göre nüfus ve artış hızları ile 2023 yılı nüfus projeksiyonlarında Batman il nüfusu 2017 yılı itibariyle 585282 olup, 2023 yılında \%16.3 artış hızıyla 645509 olması beklenmektedir (Anonim 2018a). 


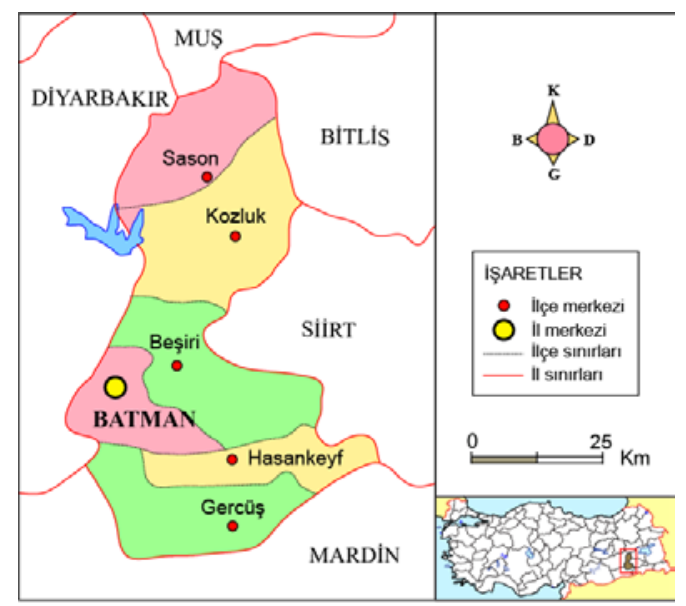

Şekil 1. Batman İli coğrafik konumu.

\section{İklim Özellikleri}

Batman İl'i karasal iklim özelliği göstermektedir. Karasal iklimin genel bir karakteristiği olarak, yaz mevsiminde aşırı sıcak ve kurak ancak buna karşın kış mevsiminde ise soğuk ve kar yağışlı olması, bu ilde de kendini göstermektedir (Çizelge 1). Çizelgenin incelenmesinden görüleceği üzere sıcaklık değişimleri oldukça keskin sınırlar göstermektedir. Yılın en sıcak ayları olan Temmuz-Ağustos aylarında en yüksek sıcaklık değerleri $39.1{ }^{\circ} \mathrm{C}^{\prime}$ ye çıkarken ortalama en düşük sıcaklık $-1.5^{\circ} \mathrm{C}$ 'ye kadar düşebilmektedir. İl'de en yüksek ve en düşük sıcaklıklar sırasıyla $48.8{ }^{\circ} \mathrm{C}$ ile $-24{ }^{\circ} \mathrm{C}$ arasında değişism göstermektedir. Yağış rejiminin dağılımı bölgede oldukça düzensizdir. Yılın en sıcak ayları olan Temmuz-Ağustos aylarında, sıcaklığa bağlı olarak yağışın bu aylarda en düşük düzeyde olması $(<1.0 \mathrm{~kg})$ ve yıllık ortalama yağışlı gün sayısı 77 iken, aylık ortalama toplam yağış miktarı ise $487.5 \mathrm{~kg} / \mathrm{m}^{2}$ olarak gerçekleşmektedir. İlde ortalama güneşlenme süresi Haziran-Eylül aylarında 12 saatin üzerinde yaşanmakta olup, bu dönemlerde yağışların azlığı nedeniyle bölgede evapotranspirasyonun yüksek olması sonucu sulama gereksinimi de doğal olarak artmaktadır. İlde hakim rüzgarlar, doğu yönünden esmektedir. Karasal iklimin bir diğer sonucu olan gece ve gündüz sıcaklık farklılıkları da belirgin olarak yaşanmaktadır (Anonim 2018c).

Çizelge 1. Batman İline ait meteorolojik veriler (Ölçüm periyodu 1963-2017)

\begin{tabular}{|c|c|c|c|c|c|c|c|c|c|c|c|c|}
\hline & I & II & III & IV & V & VI & VII & VIII & IX & $\bar{X}$ & XI & XII \\
\hline Ortalama Sicaklık $\left({ }^{\circ} \mathrm{C}\right)$ & 2.6 & 5.0 & 9.6 & 14.6 & 19.8 & 26.6 & 31.2 & 30.2 & 24.9 & 17.7 & 9.8 & 4.6 \\
\hline $\begin{array}{l}\text { Ortalama En Yüksek } \\
\text { Sicaklık }\left({ }^{\circ} \mathrm{C}\right)\end{array}$ & 7.5 & 10.5 & 15.8 & 21.6 & 27.6 & 34.8 & 39.1 & 39.1 & 34.4 & 26.6 & 16.9 & 9.6 \\
\hline $\begin{array}{l}\text { Ortalama En Düşük } \\
\text { Sicaklık }\left({ }^{\circ} \mathrm{C}\right)\end{array}$ & -1.5 & 0.0 & 3.6 & 7.9 & 11.4 & 15.8 & 20.3 & 19.7 & 15.0 & 10.0 & 4.0 & 0.3 \\
\hline $\begin{array}{l}\text { Ortalama Güneşlenme } \\
\text { Süresi (saat) }\end{array}$ & 3.1 & 4.5 & 5.5 & 7.2 & 9.0 & 11.5 & 11.8 & 11.1 & 9.7 & 6.9 & 5.2 & 3.0 \\
\hline $\begin{array}{l}\text { Ortalama Yağışlı Gün } \\
\text { Sayısı }\end{array}$ & 10.7 & 10.2 & 11.5 & 11.4 & 8.3 & 2.2 & 0.3 & 0.3 & 1.0 & 5.7 & 7.4 & 10.0 \\
\hline $\begin{array}{lr}\text { Aylık } & \text { Toplam Yağış } \\
\text { Miktarı } & \text { Ortalaması } \\
(\mathrm{mm}) & \end{array}$ & 61.3 & 67.0 & 75.6 & 73.3 & 46.1 & 7.1 & 0.6 & 0.7 & 3.8 & 32.0 & 54.4 & 65.6 \\
\hline En Yüksek Sicaklık $\left({ }^{\circ} \mathrm{C}\right)$ & 18.6 & 24.6 & 30.6 & 35.8 & 42.0 & 45.1 & 48.8 & 46.2 & 43.8 & 37.0 & 36.6 & 23.0 \\
\hline En Düşük Sicaklık $\left({ }^{\circ} \mathrm{C}\right)$ & -24.0 & -22.2 & -17.0 & -9.0 & 0.9 & 5.0 & 11.8 & 11.1 & 4.1 & -3.0 & -7.8 & -23.0 \\
\hline
\end{tabular}

\section{Toprak ve Su Kaynakları}

\section{Toprak Kaynaklarl Potansiyeli}

\section{$\underline{\text { Arazi varlığg ve tarımda kullanılabilme durumu }}$}

İlin toplam arazi varlığı 4659210 da olup, bunun \%34'lük oranına karşılık gelen 1569801 da alanda tarım yapılabilmektedir. Bunu en yakından takip eden ve \%40 oranında bir büyüklüğe sahip olan tarım dış1 araziler 1868 944 da'lık alanı oluşturmaktadır. İlin coğrafik yapısı gereği kuzey, kuzeydoğu ve güney taraflarını kaplayan dağlık alanlar, 814540 da ile \%17'lik paya sahiptir. Toplam mera alanı ise \% 9 olup, 405925 da'dır. Batman İli arazi varlığının ilçeler düzeyinde genel dağılımı Çizelge 2.'de verilmiştir. 
Çizelge 2. Batman ili arazilerinin ilçeler düzeyinde genel dağılımı (da)

\begin{tabular}{|c|c|c|c|c|c|c|c|c|}
\hline Arazinin Cinsi & Merkez & Beşiri & Gercüş & Hasankeyf & Kozluk & Sason & Toplam & $\begin{array}{c}\text { Yüzde } \\
(\%)\end{array}$ \\
\hline $\begin{array}{l}\text { Tarım Arazisi } \\
\text { Toplamı }\end{array}$ & 251216 & 592624 & 348589 & 58736 & 288121 & 30515 & 1569801 & 34 \\
\hline Mer’a Arazisi & 139531 & 181961 & 7878 & 8297 & 68258 & 0 & 405925 & 9 \\
\hline Orman Arazisi & 70675 & 42450 & 120325 & 37400 & 175090 & 368600 & 814540 & 17 \\
\hline $\begin{array}{l}\text { Tarıma } \\
\text { Elverişsiz Arazi }\end{array}$ & 93393 & 128099 & 413912 & 445655 & 455321 & 332564 & 1868944 & 40 \\
\hline $\begin{array}{l}\text { GENEL } \\
\text { TOPLAM }\end{array}$ & 554815 & 945134 & 890704 & 550088 & 986790 & 731679 & 4659210 & 100 \\
\hline
\end{tabular}

İlin mevcut arazi kullanın durumuna göre $\% 9$ oranındaki mera alanları 6 ilçe ve 54 mahalleye dağılmış durumdadır. Merkez ve Beşiri ilçelerinde 2001-2017 yılları arasında mera sslah ve amenajmanı kapsamında projeler yürütülerek tamamlanmıştır. Bu kapsamda belirtilen alanlarda mera arazilerine gübreleme, yem bitkisi ekimi ve diğer mera sslah uygulamaları yapılmıştır. Aynı ilçelerde 2016 yılında başlatılan diğer mera sslah projelerinin ise 2020 yılında tamamlanması öngörülmektedir. Yapılan mera 1slah çalışmaları yeterli gibi görülse de uygulamaların diğer mera alanlarına yaygınlaştııılması, hayvancılık faaliyetlerinin yoğun yapıldığı bölgelerde ihtiyaç duyulan mera ve otlak alanlarının korunmasına önemli oranda katkılar sağlayacaktır.

\section{Tarım topraklarının bazı özellikleri ve Kullanım Durumu}

Batman il toprakları, büyük oranda organik madde bakımından fakir olmasına karşın potasyum yönünden oldukça zengin, fosfor ve diğer bitki besin maddeleri bakımından ortak özelliklere sahip bir yapıdadır. Ağırlıklı olarak alkalik özellik gösteren il toprakları, toprak textürü yönünden büyük oranda killi, kumlu ve humuslu yapıya sahiptir. Toprak bünyesinin organik madde bakımından düşük olması sonucu, toprakların su tutma kapasiteleri, toprak havalanması azalarak sıkışıklığın azalmasına, optimum bitki gelişme ve kök bölgesi koşullarının bozulmasına neden olmaktadır. Bunun sonucu olarak da toprakların geç tava gelmesine, ekim-dikim faaliyetlerinin gecikmesine neden olmaktadır. Tarım topraklarında yeterince nadas alanlarının bırakılmaması, organik madde azalmasına ve buna bağlı olarak verim düşüklüğüne neden olmaktadır. Karasal iklimin bir sonucu olarak, Merkez ilçe ile birlikte Kozluk, Beşiri ve Hasankeyf ilçelerinin güney taraflarında oldukça zayıf karakterli ve bozkır görüntüsünde, bitki örtüsünün fakir olduğu alanlar bulunmaktadır. Bu alanlarda bitki örtüsünün oldukça zayıf karakterli bir yapı ve çeşitlilik göstermesi sonucu, rüzgâr erozyonu bu bölgelerde etkili olabilmektedir. Çınar, ardıç, ceviz, bıttım ve meşe gibi orman ağaçları ile kaplı, koruluk ve bozuk orman alanları, ilin daha çok Gercüş, Sason ve Kozluk ilçesinin kuzey taraflarında görülmektedir. İlin arazi kullanım ve kabiliyet sınıflarına göre dağılımları incelendiğinde, il topraklarının çok büyük oranda (\% 41) tarıma elverişli olmayan 190735 ha'lık VII. ve VIII. sınıf alanlar oluşturmaktadır (Anonim, 2018d). Bu alanlar, toplam il alanlarının \%34 ile 156980 ha'lık I-IV sınıf alanlar ve \% 25.3 ile 118206 ha'dan oluşan V. ve VI. sınıf araziler takip etmektedir. V. ve VIII. gurup topraklar, \%66 oranında işlemeli tarıma elverişli olmayan arazilerden oluşmaktadır (Çizelge 3). Büyük toprak grupları bakımından, Batman toprakları çoğunlukla kahverengi orman toprakları ile kahverengi topraklardan oluştuğu, daha az oranda ise alüvyal ve kolüvyal guruplardan oluşturmaktadır (Anonim, 2018b).

Çizelge 3. Arazi kullanım kabiliyet sınıfları ve oranları

\begin{tabular}{lcc}
\hline Arazi Sınıfi & Alanı (ha) & $\begin{array}{c}\text { Tarım Arazilerinin } \\
\text { Oranı (\%) }\end{array}$ \\
\hline 1.sınıf Arazi & 34650 & 7.4 \\
2.sinıf Arazi & 23614 & 5.0 \\
3.sınıf Arazi & 25721 & 5.5 \\
4.sınıf Arazi & 72995 & 15.6 \\
Tarım Arazileri Toplamı & $\mathbf{1 5 6 9 8 0}$ & $\mathbf{3 4 . 0}$ \\
5-6.sınıf Arazi & 118206 & 25.3 \\
7-8.sinıf Arazi & 190735 & 41.0 \\
Toplam & $\mathbf{4 6 5 9 2 1}$ & $\mathbf{1 0 0}$ \\
\hline
\end{tabular}

Batman İlinde tarımsal faaliyetler, yetiştiricilikteki çeşitliliğe ve vejetasyon süreleri bakımından yılın tamamına yayılmış durumdadır. Buğday, arpa, mercimek, nohut tarımı, eylül-ekim aylarında başlayarak, mayıs-haziran aylarında hasat yapılmaktadır. Ayrıca nisan sonu ve mayıs ayı başlarında pamuk tarımı başlamakta ve kasım sonu ile aralık başına kadar devam etmektedir. Özellikle sulanan ve sulamaya açılan alanlarda yoğunluklu olarak birinci ürün dane mısır yetiştiriciliği yapılmaktadır. İl yüzölçümü 465921 ha olup, bunun \% 34'ünü (156980 ha) tarım yapılan alanlar oluşturmaktadır. İlde daha çok tarla tarımı 78853 ha'lık bir alanda sürdürülürken, meyve ve sebze alanı olarak 14245 ha alan kullanılmaktadır (Çizelge 4). Tarla tarımı yapılan alanın 67128 ha' lık kısmında kuru tarım yapılmakta olup, bu alanlarda buğday, arpa, kırmızı mercimek ve nohut üretimi yapılmaktadır. Geriye kalan 11725 ha'lık alanda 
ise sulu koşullarda mısır ve pamuk yetiştiriciliği yaygın olarak yürütülmektedir. Benzer olarak sebze yetiştiriciliği yapılan 2906 ha'lık alanda ise yaprağı tüketilen sebzeler ile kavun, karpuz, biber, patlıcan ve kabak gibi sebzeler yetiştirilmektedir. Batman ili meyvecilik üretimi bakımından önemli potansiyele sahiptir. Meyvecilik faaliyetin yürütüldüğü 11335 ha'lık alanda ana ürün olarak antepfıstığı 3881 ha'lık alan ile ilk sırada yer alırken 1646 ton üretim değerine sahiptir. Bunu sofralık çekirdekli üzüm çeşidi takip etmekte olup 6323 ha alanda bağcılık faaliyeti sürdürülmektedir (Anonim 2018d).

Çizelge 4. Arazi kullanım durumları (da)

\begin{tabular}{|c|c|c|c|c|c|c|c|c|}
\hline \multicolumn{2}{|c|}{ Arazinin Cinsi } & Merkez & Beşiri & Gercüş & Hasankeyf & Kozluk & Sason & Toplam \\
\hline \multirow{3}{*}{$\begin{array}{l}\text { Tahıllar ve } \\
\text { diğer } \\
\text { bitkisel } \\
\text { ürünlerin } \\
\text { alanı }\end{array}$} & $\begin{array}{l}\text { Tarla } \\
\text { Arazisi } \\
\text { (Sulu) }\end{array}$ & 40524 & 35800 & 185 & 1250 & 39290 & 201 & 117250 \\
\hline & $\begin{array}{l}\text { Tarla } \\
\text { Arazisi } \\
\text { (Kuru) }\end{array}$ & 99068 & 300000 & 96342 & 8035 & 167621 & 217 & 671283 \\
\hline & $\begin{array}{l}\text { Toplam } \\
\text { Alan }\end{array}$ & 139592 & 335800 & 96527 & 9285 & 206911 & 418 & 788533 \\
\hline \multicolumn{2}{|l|}{ Nadas alanı } & 150 & 1000 & 175 & 1000 & 1000 & 580 & 3905 \\
\hline \multirow{3}{*}{$\begin{array}{l}\text { Meyve } \\
\text { alanı }\end{array}$} & $\begin{array}{l}\text { Bağ } \\
\text { Arazisi }\end{array}$ & 1000 & 2500 & 49950 & 5300 & 3975 & 500 & 63225 \\
\hline & $\begin{array}{l}\text { Bahçe } \\
\text { Arazisi }\end{array}$ & 4550 & 23425 & 14299 & 3020 & 3520 & 7 & 48921 \\
\hline & $\begin{array}{l}\text { Toplam } \\
\text { Alan }\end{array}$ & 5550 & 25925 & 64349 & 8320 & 7595 & 1607 & 113346 \\
\hline \multirow{2}{*}{\multicolumn{2}{|c|}{$\begin{array}{l}\text { Sebze bahçeleri } \\
\text { Tarım arazileri } \\
\text { toplamı }\end{array}$}} & 4621 & 6500 & 7.221 & 3480 & 6900 & 386 & 29108 \\
\hline & & 149913 & 369225 & 168272 & 22085 & 222406 & 2991 & 934892 \\
\hline
\end{tabular}

Su Kaynaklarl Potansiyeli

\section{$\underline{\text { Yeralt suyu potansiyeli }}$}

Batman ili yeraltı su kaynakları bakımından oldukça zengindir. Sulanabilir alanların bir bölümünde üreticiler kendi olanakları ile açtıkları yeraltı sondajlarından sağlanan su ile sulama yapmaktadırlar. Batman çayı verimli alüvyonları ile Batman ovasının bir kesiminde yayılım gösteren kumtaşı ve çakıltaşı birimlerinden oluşan lahti formasyonu, ilin yeraltı suyu bakımından verimli alanlarını oluşturmaktadır. Verimli alüvyonları, İlin mevcut içme suyunu sağlamakta olup bölgede yeraltı su seviyesi 9-10 m arasında değişmektedir. Lahti formasyonunun olduğu ilin güneydoğu kesimlerinde yeraltı su seviyesi 25-30 m arasında değişmekte olup, diğer kesimleri yeraltı suyu bakımından oldukça verimsizdir. Ayrıca ilin $12 \mathrm{~km}$ güneybatısında Diyarbakır sınırları içerisinde yaklaşık $6.5 \mathrm{~m}^{3} / \mathrm{s}$ debiye sahip kalker aküferden boşalan Zilek kaynakları da önemli bir su potansiyelidir (Anonim 2018b).

\section{$\underline{\text { Barajlar }}$}

Batman İl merkezinden geçen ve etrafında verimli düzlüklerin bulunduğu Batman çayı üzerinde, sulama, taşkın önleme ve enerji üretim amaçlı inşa edilmiş olan Batman barajı, Diyarbakır il sınırları içerisinde kalmaktadır. Türkiye'nin 81. ve Diyarbakır'ın 2. büyük hidroelektrik santralidir. Bununla birlikte, Batman'ın Kozluk İlçesinde Yanarsu çayı üzerinde inşa edilen ve Özel bir enerji firması tarafından işletilen Garzan (Fernas) Barajı ile sulama amaçlı olarak, 1974 yılında işletmeye açılan Batman-Silvan sulama regülatörü ilin diğer sulama suyu kaynakları olarak hizmet vermektedir (Çizelge 5). Batman barajı, kil çekirdekli kaya dolgu tipinde sulama ve enerji amaçlı inşa edilmiş ve 2003 yılında işletmeye alınmıştır. Barajın akarsu yatağından yüksekliği $85 \mathrm{~m}$ olup, gövde hacmi $7181 \mathrm{~m}^{3}$, normal su kotunda göl hacmi 1175 hm³, yaklaşık $49 \mathrm{~km}^{2}$ normal su kotunda göl alanına sahiptir. İnşa amacı sulama ve enerji olduğundan, 37351 ha alanın sulanması planlama ölçütü olarak alınmıştır. Baraj, 198 MW kurulu gücü ile $483 \mathrm{Gwh} / \mathrm{y}$ 1l yıllık ortalama enerji üretimi gerçekleştirmektedir (Anonim, 2018b). Batman barajından sulama yapılan alanlar için planlama sulama modülü 1.17 l/sn/ha olarak hesaplanmış ve belirlenmiştir. Garzan baraj1 ve HES, $52 \mathrm{MW}$ kurulu gücü ile Türkiye'nin 225. ve Batman'ın ise en büyük enerji santralidir. Enerji üretimine 2015 y1lında başlamıştır. Batman-Silvan sulama regülatörü ise, tamamen sulama amaçlı planlanarak ve Batman çayı üzerinde inşa edilerek sulamaya açılmıştır. Regülatör, dolu gövdeli sabit tip ve savaklı olarak inşa edilmiş olup, cazibe sulama ile net 7590 ha'lık bir alanı sulaması öngörülmüştür (Anonim 2018e). 
Çizelge 5. Batman ili su kaynakları

\begin{tabular}{|c|c|c|c|c|c|c|}
\hline Faaliyet Ad1 & $\begin{array}{c}\text { İşletme } \\
\text { Alındığ1 Y1l }\end{array}$ & $\begin{array}{l}\text { Faaliyetin } \\
\text { Yeri }\end{array}$ & Kapasitesi & Amac1 & $\begin{array}{l}\text { Faaliyet } \\
\text { Durumu }\end{array}$ & $\begin{array}{c}\text { Sulama } \\
\text { Alanı } \\
\text { (ha) }\end{array}$ \\
\hline $\begin{array}{l}\text { Batman Baraj1 } \\
\text { HES }\end{array}$ & 2003 & $\begin{array}{l}\text { Batman Çayı } \\
\text { üzerinde }\end{array}$ & $\begin{array}{l}483 \text { GWh/y1l (198 } \\
\text { MW) }\end{array}$ & $\begin{array}{l}\text { Sulama, } \\
\text { Enerji }\end{array}$ & İşletmede & \\
\hline Garzan Baraj1 HES & 2015 & $\begin{array}{l}\text { Yanarsu Çayı } \\
\text { üzerinde }\end{array}$ & $\begin{array}{l}198 \mathrm{GWh} / \mathrm{y} 1 \mathrm{l}(52 \\
\text { MW) }\end{array}$ & $\begin{array}{l}\text { Sulama, } \\
\text { Enerji }\end{array}$ & İşletmede & \\
\hline $\begin{array}{l}\text { Batman-Silvan } \\
\text { Sulama Regülatörü }\end{array}$ & 1974 & Batman Çayı & & Sulama & İşletmede & 7590 \\
\hline
\end{tabular}

\section{$\underline{\text { Akarsular }}$}

Batman İl sınırları içerisinde bulunan en önemli akarsular Dicle nehrinin kollarını oluşturan Garzan çayı, Batman çayı ile Sason çaylarıdır (Çizelge 6). Batman il sınırları içerisinde Dicle nehrinin kollarını oluşturan Garzan ve Batman çayları bulunmaktadır. Batman çayı ise, esas olarak Kulp çayı ve Sarım Çayı (Diyarbakır sınırları içerisinde) ile Zori (Serkan) ve Talorin çayları (Batman sınırları içerisinde) gibi kollardan oluşmaktadır. İl sınırları içerisinde $124 \mathrm{~km}$ ile en uzun akış yoluna sahip olan Batman çayı, $126.9 \mathrm{~m}^{3} / \mathrm{s}^{\prime}$ lik debiyle yıllık ortalama 4.2 milyar $\mathrm{m}^{3}$ su potansiyeline sahiptir. Garzan çayının yıllık ortalama su potansiyeli ise 830 milyon $\mathrm{m}^{3}$ 'dür. Batman çayı, üzerinde kurulu bulunan Batman barajı ve Batman-Silvan Sulama Regülatörüne su kaynağı olarak hizmet etmektedir (Anonim 2018b).

Çizelge 6. Batman ili akarsuları (DSİ 2017)

\begin{tabular}{lccccc}
\hline Akarsu İsmi & $\begin{array}{c}\text { Toplam } \\
\text { Uzunluğu }(\mathrm{km})\end{array}$ & $\begin{array}{c}\text { İl Sinırları İçindeki } \\
\text { Uzunluğu }(\mathrm{km})\end{array}$ & $\begin{array}{c}\text { Debisi } \\
\left(\mathrm{m}^{3} / \mathrm{sn}\right)\end{array}$ & $\begin{array}{c}\text { Kolu Olduğu } \\
\text { Akarsu }\end{array}$ & $\begin{array}{c}\text { Kullanım } \\
\text { Amacı }\end{array}$ \\
\hline Dicle Nehri & 530 & 86 & 300 & Dicle & Sulama, Enerji \\
Garzan Çayı & 168 & 110 & 49.3 & Dicle & Sulama, Enerji \\
Batman Çayı & 144 & 124 & 126.9 & Dicle & Sulama, Enerji \\
Sason Çayı & 65 & 65 & 142.2 & Batman & Enerji \\
Serkan (Zori) Çayı & 78 & 58 & 17 & Batman & Sulama \\
\hline
\end{tabular}

\section{Doğal Göller, Göletler ve Rezervuarlar}

Batman sınırları içerisinde doğal gölet bulunmamakla beraber, iki adet sulama göleti bulunmaktadır. DSİ tarafından 1984 yılında işletmeye alınan Gercüş-Kırkat Göleti ile Kozluk Ceffan göletleri, sulama alanlarına hizmet etmektedir (Çizelge 7). Gercüş-Kırkat göleti, Batman ili, Gercüş ilçesine 8 km uzaklıkta olup, Dicle havzasında bulunmaktadır. Nehir deresi üzerine inşa edilen gölet, 350 ha alanı sulamaktadır. İlin diğer göleti ise Ceffan (Garzan) göleti olup, Ceffan deresi üzerinde inşa edilmiş ve toplam 332 ha alanı sulamaktadır (Anonim 2018b).

Çizelge 7. Batman ili sulama Göletleri

\begin{tabular}{|c|c|c|c|c|c|}
\hline Göletin Ad1 & Tipi & $\begin{array}{l}\text { Göl hacmi, } \\
\mathrm{m}^{3}\end{array}$ & $\begin{array}{l}\text { Sulama Alanı } \\
\text { (net), ha }\end{array}$ & $\begin{array}{l}\text { Çekilen Su } \\
\text { Miktarı, }\left(\mathrm{m}^{3}\right)\end{array}$ & $\begin{array}{c}\text { Kullanım } \\
\text { Amaci }\end{array}$ \\
\hline $\begin{array}{l}\text { Gercüş-Kırkat } \\
\text { Göleti }\end{array}$ & $\begin{array}{c}\text { Homojen Toprak } \\
\text { Dolgu }\end{array}$ & 3155210 & 350 & 2549060 & Sulama \\
\hline $\begin{array}{l}\text { Kozluk- } \\
\text { Ceffan Göleti }\end{array}$ & $\begin{array}{l}\text { Kil Çekirdekli Kaya } \\
\text { Dolgu }\end{array}$ & 6845000 & 332 & 5420000 & Sulama \\
\hline
\end{tabular}

\section{Sulama}

Batman ili toprakları, Tarım Master Planı kayıtlarına göre 469400 ha olarak verilmekte olup, bunun \%30’luk kısmına karşılık gelen 142620 ha'lık alanda tarım yapılabilmektedir. Sulu tarım yapılan alan ise, toplam alanın \% $15^{\prime}$ 'lik kısmı olan yaklaşık 21020 ha alanında yapılmaktadır (Anonim 2005). Ancak son yılların verilerine göre il coğrafyasında olan değişiklikler, kentsel gelişim, imar planlarında olan değişmeler sonucu, İlin toplam alanı 465921 ha ve bu alanın \% 34'ü tarımsal faaliyetlerde kullanıldığı ve bunun da 156980 ha olduğu kayıtlardan anlaşılmaktadır (Anonim 2018d) . Bu durumda sulanan tarım alanlarının \% 15 olduğu göz önüne alındığında ve bu oranın değişmediği varsayıldığında, sulu tarım alanının 23547 ha alan olduğu tahmin edilmektedir.

Tarım alanlarının sulanmasında yüzey sulama yöntemlerinin yanı sıra bazı tarla tarımı yapılan alanlarda basınçlı sulama yöntemlerinden yağmurlama, tamburlu yağmurlama yöntemleri kullanılmaktadır. Bununla beraber, az da olsa seracılık faaliyetlerinin yapıldığı bölgelerde damla sulama yöntemi de kullanılmaktadır. 
İlde sulama faaliyetleri, Sulama Birlikleri aracılığıyla yürütülmektedir. Bu amaçla kurulan 4 adet Sulama Birliği içerisinde (Çizelge 8) Batman Sağ Sahil ve Batman Sol Sahil Sulama Birlikleri, Batman barajından alınan sulama suyunu faaliyet alanında dağıtarak üreticilere ulaştırmaktadır. Garzan-Kozluk Sulama Birliği ile Batman-Silvan Sulama Birlikleri ise, sulama suyunu önceleri regülatörden alırken, daha sonra Garzan barajının yapılmasıyla bu barajdan almaya başlamıştır. Batman projesi sulamaları temel olarak 2 sulama alanından oluşmaktadır. Batman Sağ Sahil sulama alanı ile 18758 ha proje alanı olarak belirlenmiş ve 3000 ha işletme alanına sahiptir. Kaynak olarak Batman barajından yararlanılmakta olup, sulama alanları coğrafik olarak Diyarbakır sınırları içerisindedir. Batman Sol Sahil Sulama alanı ise 18593 ha proje alanı ve 5000 ha işletme alanına sahip olup, Batman topraklarını sulamaktadır (Anonim, 2018g).

Çizelge 8. Batman ili Sulama Birlikleri

\begin{tabular}{|c|c|c|c|c|c|}
\hline Sulama Birlikleri & $\begin{array}{c}\text { İşletmeye } \\
\text { Açıldığı Tarih }\end{array}$ & Su Kaynağı & $\begin{array}{c}\text { Proje } \\
\text { Alanı } \\
\text { (ha) }\end{array}$ & $\begin{array}{c}\text { Net Sulama } \\
\text { Alanı (ha) }\end{array}$ & $\begin{array}{c}\text { Ekim Alan1* } \\
\text { (ha) }\end{array}$ \\
\hline Batman Sağ Sahil SB & 2006 & Batman Barajı & 18758 & 5000 & 5300 \\
\hline Batman Sol Sahil SB & 2007 & Batman Baraj1 & 18593 & 3000 & 2430 \\
\hline Garzan-Kozluk SB & 1990 & $\begin{array}{c}\text { Garzan Barajı } \\
\text { Garzan Barajı ve }\end{array}$ & 3700 & 1500 & 1500 \\
\hline Batman-Silvan SB & 1972 & $\begin{array}{l}\text { Batman-Silvan sulama } \\
\text { regülatörü }\end{array}$ & 7590 & & 4740 \\
\hline
\end{tabular}

*2017 y1lı değerleridir.

Batman Sol Sulama Birliği faaliyet alanı, halen cazibe (7 107 ha), pompaj1 (3 914 ha)( $\mathrm{P}_{1}$ ) ve pompaj2 (3 157 ha) ( $\left.\mathrm{P}_{2}\right)$ olmak üzere toplam 14178 ha'dan oluşmaktadır. Aktif olarak sulama yapılan alan, cazibe kısmından oluşmaktadır. Pompaj sulama alanında bazı sanatsal yapıların halen tamamlanmamış olması nedeniyle, ilgili kamu kurumu tarafından Sulama Birliğine devri yapılmamıştır. Bu nedenle sulama alanı, aktif olarak cazibe ile sulanan alandan oluşmaktadır (Çizelge 9).

Çizelge 9. Batman Sol Sahil Sulama Birliği sulama alanı

\begin{tabular}{|c|c|c|c|c|c|c|c|c|}
\hline \multirow{3}{*}{ Su Kaynağ1 } & \multirow{3}{*}{$\begin{array}{c}\mathrm{Su} \\
\text { Alma } \\
\text { Şekli }\end{array}$} & \multirow{3}{*}{$\begin{array}{l}\text { Sulama } \\
\text { Kaynağı }\end{array}$} & \multicolumn{2}{|c|}{ Sulanan } & \multicolumn{3}{|c|}{ Sulanmayan } & \multirow{2}{*}{$\begin{array}{c}\text { Sol Sahil } \\
\text { Toplam Sulama } \\
\text { Alanı (ha) } \\
\end{array}$} \\
\hline & & & & & & & & \\
\hline & & & $\begin{array}{c}\text { Alan } \\
\text { (ha) }\end{array}$ & $\%$ & Sulanmama Nedeni & $\begin{array}{c}\text { Alan } \\
\text { (ha) }\end{array}$ & $\%$ & \\
\hline \multirow{7}{*}{ Batman Baraj1 } & \multirow{7}{*}{ Cazibe } & Birlik & 2410 & 34 & \multirow{6}{*}{$\begin{array}{l}\text { Topoğrafik } \\
\text { Havaalanı ve Konut } \\
\text { Yapılaşması } \\
\text { Nadas } \\
\text { Sulanmayan buğday } \\
\text { ve dere suyu ile } \\
\text { sulanan sebze }\end{array}$} & 100 & 3 & 7107 \\
\hline & & Çiftçi & & & & 1000 & 27 & \\
\hline & & Olanakları & 1000 & 14 & & 100 & 0 & \\
\hline & & & & & & 100 & 3 & \\
\hline & & & & & & 2497 & 67 & \\
\hline & & & & & & 3697 & 100 & \\
\hline & & TOPLAM & 3410 & 48 & & 3697 & 52 & 7107 \\
\hline
\end{tabular}

Toplam 7107 ha'lık sulama alanının, 2410 ha'lık kısmı, Sulama Birliği tarafından işletilirken, 1000 ha'lık alan çiftçi olanakları ile ve cazibe yöntemiyle sulanmaktadır. Geriye kalan ve toplam sulama alanının \%52'sini oluşturan 3697 ha alan ise havaalanı, kentsel yerleşim gibi tarım dışı alanlarla, sulanmayan ya da dere suyu ile sulanan sebzelik alanları oluşturmaktadır (Anonim 2017). Batman sol sulama şebekesi basınçlı, yarı basınçlı ve cazibeli sulama olarak sanatsal yapılara sahiptir. Ancak çiftçi alışkanlıkları ve tercihleri nedeniyle bölgede basınçlı sulama tercih edilmemektedir. Sulanan alanın \% 95 'i cazibeli, \%5 'i yağmurlama sistemleri ile sulama yapılmaktadır (Anonim 2018g).

\section{Sorunlar ve Çözüm Önerileri}

Tarımda kullanılan sulama sularının etkin ve sürdürülebilirliğinin sağlanması amacıyla, Batman çayına boşaltılan edilen arıtma çıktı sularının yeniden kullanım olanaklarının araştırılması, su kaynaklarının artırılması ve geliştirilmesinin yanı sıra tarımsal verimliliği de doğrudan etkileyecektir.

Batman çayı su kalitesinin korunması bakımından, sulama kaynaklarına olan sanayi ve evsel atıkların zararlılık düzeyinin azaltılmasına yönelik çalışmalar yapılmalıdır. Bu amaçla ilgili Kamu kurum ve Kuruluşları ile ilgili Belediyeler koordineli olarak çalışmalı, yeni projeler geliştirilmeli ve uygulanmalıdır. 
Sulanabilir alanlara su sağlayan iletim kanallarından olan randıman kayıpları dikkatle takip edilerek, kayıp-kaçak oranını artıran sebeplerin ortadan kaldırılmasına yönelik önlemler geliştirilmeli, sulama yapılan tarım alanlarında suyun doğru ve etkin kullanılarak sulama randımanlarının artırılması amacıyla eğitim ve iyileştirici çalışmalar yapılmalıdır. Böylece, su kullanım etkinliğinin artırılması ve kaynakların sürdürülebilir kullanım süreçleri de geliştirilebileceği gibi üreticilerin ekonomik faydalanma oranları ve gelir düzeyleri de olumlu etkilenecektir.

Tarım alanlarında arazilerin korunması ve etkin kullanılmasının sağlanması için arazi kullanım planlarının yapılması ve uygulanması bir zorunluluktur. Böylece tarımsal verimliliğin artırılması olanaklı olabileceği gibi toprak ve su kaynaklarının daha etkin ve kullanımında süreklilik sağlanmış olacaktır.

Tarımda aşırı su kullanımı, sulu tarımın önemli sorunlarındandır. Sulama suyunun aşırı ve bilinçsiz kullanımı, doğal ekosistemin bozulmasının yanı sıra toprak ve su kayıplarının artmasına, toprak strüktüründe bozulmalara, bitki kök bölgesinin bitki yetişme ortamının bozulmasına ve toprakların kullanım ömrünün kısalmasına neden olmaktadır. Bilinçsiz ve aşırı su kullanımı ya da düşük performanslı sulama uygulamaları, bölgelere göre değişmekle birlikte (Siirt ilinde \%50'nin altında) yaygın olarak çok düşük performansla sulama yapılmaktadır (Anonim 2012). Sulamanın yaygınlaşmaya başladığ 1 ilk yıllarda GAP bölgesinde 0.15-7 kat daha fazla aşırı su kullanılması, tarım topraklarının elverişsiz hale gelmesine ve toprakların tarımsal kaynaklı kirlenmeleri sonucunu da beraberinde getirmektedir (Tekinel ve ark. 2002). Sulu tarıma geçilen bölgelerde daha önceleri yetiştirilemeyen bazı ürünlerin, sulu tarımla birlikte yetiştirilmeye başlanılmış olması, ürün deseni ve arazi kullanım planlamasında da farklılıkların oluşmasına neden olmaktadır. Ancak, sulu tarım teknikleri ve uygulamaları konusunda ön bilgiye sahip olmayan bölge çiftçisi önemli oranda verim kaybına da neden olmaktadır (Kanber ve ark. 1999). Sulu tarım konusunda ön bilgiye sahip olmayan üreticilerin öncelikle buna hazır hale getirilmeleri, bilinçli su kullanımı, geri kazanılması olanaklı olmayan toprakların korunmasına özen gösterilmesi ve gereksiz yere tarım dışı arazi kullanımına firsat verilmemesi gibi konularda hazırlık eğitimleri ile üretici bilinç düzeyi artırılmalıdır. Üreticiler, bu tür çalışmaların doğrudan kamu kurumları tarafından yapılmasının beklentileri arasında bulunduğunu, bu konuda teşvik edici finansal kaynak kullandırmanın daha etkin olduğunu belirtmektedirler (Aydın ve Saltuk 2018).

Batman ili tarımsal potansiyelinin ve verimliliğinin artırılması için, çiftçi gelir düzeyinin yükseltilmesi amacıyla sürdürülebilir ve gerçekçi projeler yapılmalıdır. Yeni tarım teknolojilerinin benimsetilmesi ve kullanımının yaygınlaştırılması, geleneksel tarım anlayışı yerine, yenilikçi ve modern tarım tekniklerinin üreticilerle buluşturulması ve uygulanmasının desteklenmesi, tarımda verimliliğin artırılması ve sürdürülebilirlik için yerinde bir ön tedbir olacaktır. Bunun için entansif tarım teknikleri üreticiye benimsetilmeli, hizmet üreten kamu kurum ve kuruluşları tarafından gerekli teknik ve idari altyapı sağlanmalı, toprak ve su kaynaklarının yerinde ve ekonomik kullanımı üreticilere benimsetilmelidir.

Sulanan ve sulamaya açılan alanlarda ürün deseni olarak çeşitliliğin olmaması, sulama zamanlarının aynı dönemlere rastlaması, dolayısıyla sulama suyu ve su tüketim miktarının aynı dönemlerde maksimum seviyeye çıkmasına neden olmaktadır. Bu durum, sulanan alanların azalmasına, aşırı su kullanımı gibi sorunları da beraberinde getirmektedir. $\mathrm{Su}$ tüketiminin aynı anda maksimum düzeye çıkması sulama sanat yapılarının hasar görmesine ve verimliliğin düşmesine neden olmaktadır.

\section{Sonuç}

Toprak ve su kaynaklarının etkin ve yerinde kullanımı, tarımsal verimliliğin artırılması ve sürdürülebilirlik için oldukça önemlidir. Dünya ve ülkemiz nüfusunun artışına paralel olarak artan gida talebi, sanayi ve kentsel gelişim, küresel ısınmanın bir sonucu olarak zaten kıt kaynak olan su üzerindeki baskının artması, toprak ve suyun daha etkin kullanımını zorunlu kılmaktadır. Bu nedenle, toprak ve su kaynaklarını tahribata uğratmadan geliştirmek ve daha rasyonel su yönetimi politikaları izlemek ve uygulamak gereklidir.

Suyun kıt kaynak olmasının yanı sıra, temininde zorluk çekilmesi, su ekonomisi gibi nedenlerden dolayı, bölgede suyu daha tasarruflu ve ekonomik kullanan sulama yöntemleri yaygınlaştırılmalıdır. Bu amaçla, üreticilerin özellikle sulu tarım ve tarım teknolojileri konusunda bilgi düzeylerinin artırılmasına yönelik, ilgili kamu kurumları ve üniversiteler tarafından eğitim programları hazırlanmalı ve uygulanmalıdır.

\section{Teşekkür}

Bu çalışmaya katkı ve desteklerinden dolayı, GAP Tarımsal Eğitim ve Yayım Projesi Saha Uzmanı Zir. Müh. Sabahattin TÜZÜN, Batman Sol Sahil Sulama Birlik Başkanı Dr. Zir. Yük. Müh. Oktay KILIÇ ve Sulama Birliği Müdürü Zir. Müh. Abdurrezzak KAVAK’a teşekkürlerimi sunarım. 


\section{Kaynaklar}

Aküzüm T, Çakmak B, Gökalp Z, (2010). Türkiye’de Su Kaynakları Yönetiminin Değerlendirilmesi. TABAD Tarım Bilimleri Araştırma Dergisi. 3 (1): 67-74, 2010 ISSN:1308-3945, E-ISSN:1308-027X, www.nobel.gen tr

Anonim (2005). Batman İli Tarım Master Planı. TC. Batman Valiliğii, Gıda Tarım ve Hayvancılık İl Müdürlügüü. Batman, Sh: 40

Anonim (2012). Siirt İli-İlçeleri Mevcut Su Kaynaklarının Potansiyel Güçlerinin Saptanması, Çıktıların Yerelde ve Genelde Eşzamanlı Paylaşımı Projesi. Siirt Valiliği, Gıda Tarım ve Hayvancılık İl Müdürlüğü, DİKA-11-01DFD/15 Nolu Proje Sonuç Raporu. Siirt (Hazırlayan Prof. Dr. Mehmet ŞİMŞEK, Siirt, sh: 48

Anonim (2017). Sulama Sonuçları Değerlendirme Raporu. DSİ İşletme ve Bakım Daire Başkanlığı, Doküman Revizyon Tarihi: Kasım 2017. Diyarbakır, sh: 1-5

Anonim (2018a). TUİK. http://www.tuik.gov.tr/PreTablo.do?alt_id=1027 Erişim Tarihi: 24 Aralık, 2018

Anonim (2018b). Batman İli 2017 Yılı Çevre Durum Raporu. T.C. Batman Valiliği, Çevre ve Şehircilik İl Müdürlüğü, ÇED ve İzin Şube Müdürlügü, Batman, sh: 82

Anonim (2018c). DMIGM Web sayfas1. https://www.mgm.gov.tr/veridegerlendirme/il-ve-ilceleristatistik.aspx?k=A\&m=BATMAN Erişim Tarihi: 24 Aralık, 2018

Anonim (2018d). Batman İli 2018 Yılı Brifing Raporu. Batman Valiliği, İl Gıda Tarım ve Hayvancılık Müdürlüğü. Batman, sh:75

Anonim (2018e). Batman-Silvan Regülatör Sulaması. DSİ 10. Bölge Müdürlüğü, İşletme ve Bakım Şube Müdürlüğü. Batman-Silvan Regülatörü Tanıtma Föyü. Doküman No: F 1700 26, Yayın tarihi: Temmuz, 2009, Diyarbakır, sh:1/1

Anonim (2018f). http://www.wwf.org.tr/basin_bultenleri/raporlar/?4180/turkiyenin-su-riskleri-raporu Erişim Tarihi: 03 Aralık, 2018

Anonim (2018g). Batman Projesi Sulamaları. Batman Sol Sahil Sulama Birliği Bilgi Notu.

Anonim (2018h). https://www.kdmp.gov.tr/sayfa/su-kaynaklari Erişim Tarihi: 03 Aralık, 2018

Aydın Y., Saltuk B, (2018). Siirt Yöresi Fıstık Yetiştiricilerinin Sulama Eğilimlerinin Belirlenmesi. Süleyman Demirel Üniversitesi Ziraat Fakültesi Dergisi, 1. Uluslararası Tarımsal Yapılar ve Sulama Kongresi Özel Saylsi:119127,2018. ISSN 1304-9984, Araştırma Makalesi.

Çakmak B, (2011). Su Kaynakları ve Yönetimi. Tarımsal Yapılar ve Sulama, T.C. Anadolu Üniversitesi Yayını No: 2269, Açık Öğretim Fakültesi Yayını, No: 1266 Eskişehir, sh:134-157

Çakmak B, Gökalp Z, (2011). İklim değişikliği ve Etkin Su Kullanımı. TABAD Tarım Bilimleri Araştırma Dergisi 4 (1):87-95, 2011. ISSN:1308-3945, E-ISSN:1308-027X, www.nobel.gen.tr

DSİ, (2018). http://www.dsi.gov.tr Erişim tarihi: 30 Kasım, 2018

Kanber R, Köksal H, Ünlü M, Ödemiş B, (1999). Sulama ve Çevre İlişsileri. GAP Yöresinde Çevre Eğitimi. 4-7 Ekim 1999, Diyarbakır. Türkiye Çevre Vakfı Yayını. No. 140, Ankara, s. 195-230

Karaman S, (2006). Tokat İl’i Toprak ve Su Kaynaklarının Tarımsal Açıdan Değerlendirilmesi. GOÜ. Ziraat Fak Fakültesi Dergisi, 2006, 23 (1) 37-44

Kıymaz S, (2011). Kırşehir İ'i Toprak ve Su Kaynaklarının Tarımsal Açıdan Değerlendirilmesi. Süleyman Demirel Üniv. Ziraat Fakültesi Dergisi, 6 (2):76-85, 2011. ISSN 1304-9984, Derleme

Meriç BT, (2004). Su Kaynakları Yönetimi ve Türkiye. Jeoloji Mühendisliği Dergisi, 28 (1) 2004

Tekinel O, Ünlü M, Topaloğlu F, Kanber R, (2002). GAP Yöresinde Su Kullanımı ve Tuzluluk. KSÜ, Fen ve Mühendislik Dergisi 5 1(2002)

TUİK (2018). http://www.tuik.gov.tr/UstMenu.do?metod=temelist. Erişim tarihi: 6 Aralık, 2018

Turan T, Eren Z, (2008). Türkiye'de Su Kaynakları ve Su Politikası. TMMOB 2. Su Politikaları Kongresi. 20-22 Mart 2008, Ankara 